\title{
Low-Density Polyethylene/Polyamide/Clay Blend Nanocomposites: Effect of Morphology of Clay on Their Photooxidation Resistance
}

\author{
N. Tz. Dintcheva, ${ }^{1}$ G. Filippone, ${ }^{2}$ R. Arrigo, ${ }^{1}$ and F. P. La Mantia ${ }^{1}$ \\ ${ }^{1}$ Dipartimento di Ingegneria Chimica dei Processi e dei Materiali, Università di Palermo, Viale delle Scienze, \\ Ed. 6, 90128 Palermo, Italy \\ ${ }^{2}$ Dipartimento di Ingegneria dei Materiali e della Produzione, Università di Napoli Federico II, \\ Piazzale V. Tecchio 80, 80125 Napoli, Italy \\ Correspondence should be addressed to N. Tz. Dintcheva; nadka.dintcheva@unipa.it
}

Received 16 February 2017; Revised 10 June 2017; Accepted 6 July 2017; Published 9 August 2017

Academic Editor: Christian Brosseau

Copyright (C) 2017 N. Tz. Dintcheva et al. This is an open access article distributed under the Creative Commons Attribution License, which permits unrestricted use, distribution, and reproduction in any medium, provided the original work is properly cited.

The photooxidation behaviour of low-density polyethylene (LDPE)/polyamide (PA) blends, containing polyamide 11 (PA11) or polyamide 6 (PA6), has been investigated in the absence and presence of a small amount of commercial organomodified clay (OMMT). The polymer blends LDPE/PA11 and LDPE/PA6 at 75/25 wt./wt.\%, with and without OMMT, have been prepared by a two-step procedure: extrusion and sheet formulation. The formulated complex systems have been subjected to accurate morphological analysis in order to evaluate the effect of the OMMT presence on the refinement of the blend morphology. Furthermore, the produced sheets have been subjected to arterial UVB exposure and the variations of the mechanical properties and chemical structure of all the investigated samples have been monitored as a function of the exposure time. Finally, the rate of the photodegradation of the complex systems has been related to the morphological changes of these systems upon OMMT addition.

\section{Introduction}

The production of high-performance polymeric-based materials at a low cost remains a challenging issue from an industrial point of view [1]. Different strategies have been proposed in the scientific literature for enhancing the performance of the polymeric materials, including the formulation of polymer blends, the introduction of nanofillers, and the functionalization of polymers [2-4]. Blending polymers can be considered as a suitable economical way for the formulation of high-performance polymeric-based materials, since the proper choice of the blend constituents allows obtaining multicomponent systems whose properties go well beyond the limits predicted by the simple additivity rules based on the single component properties [5]. The macroscopic performance of polymeric blends can be further improved through the introduction of nanoparticles, such as layered silicate [6], carbon nanotubes [7], carbon black [8], and graphite [9], which, for instance, can enhance the mechanical properties of polymer-based systems due to their well-known reinforcement action [10].

As well known, the control of morphology and/or nanoparticles distribution in the polymeric phases is a key factor for the obtainment of high-performance polymerbased systems, as the macroscopic properties of these complex systems are strictly related to their microstructures [11]. Indeed, the achievement of a regular morphology may result in an unexpected increase of some performance such as mechanical and/or transport properties.

The introduction of nanoparticles, in particular layered silicates, in polymer blends can promote their morphology refinement, since the nanoclays, confined at the interface between the two polymeric phases, can enhance the interfacial adhesion and promote the morphology modifications from droplet-like to cocontinuous [12-14]. Hence, significant properties enhancement for immiscible polymer blends containing nanoparticles can be gained due to the synergism between the reinforcement action of the fillers and the 
blend microstructure changes [15]. The immiscible polyolefin/polyamide blends, employed in a variety of packaging and automotive products, have gained great interest because of their low cost, good processability, good barrier property against oxygen and humidity, and mechanical properties $[16,17]$. For this reason, the photooxidation resistance of polyolefin/polyamide polymer blends is a critical point for their employment in several outdoor applications [18]. As well known, the exposure of the polymers or polymer blends in their use conditions causes their photooxidation, with a consequent decrease of their macroscopic performance because of the variation of their chemical structure, molecular weight, and morphology $[19,20]$. This issue is exacerbated when different kinds of organomodified layered silicates are added to the polymer-based systems [21, 22]. Indeed, as well known in the literature, nanoclays have a detrimental effect on the polymer photooxidation resistance [23, 24]. Different explanations have been proposed in the literature to explain the accelerated photodegradation of nanoclay-containing polymer systems, particularly the thermal degradation of organomodifiers during processing at high temperatures, typical for processing of polymers, and the subsequent formation of acidic sites on the silicate layers [25], the presence of iron ions in the clay structures, which are able to catalyze the decomposition of the oxidized species formed during the photooxidation of the macromolecules [26], and the inactivation of the stabilizers due to their entrapment between the silicate layers [27].

According to the literature, the degradation of polyolefin/ polyamide polymer blends is a very complex phenomenon, which depends on many factors, such as the formation of radicals coming from the blend constituents and subsequent uneven recombination between these radicals, the migration of oxygen, and UV exposure [21]. It is very important to highlight that the propagation of the radicals, coming from the more UV susceptible polymer phase, that is, the polyamide, depends on the complex system morphology, which can favour or slow down the radical propagation. Besides, the changes of the complex system morphology, upon the addition of organomodified clay, can lead to the formulation of heat-resistant bio-based blends based on poly(lactic acid) [28].

However, also according to the literature, the addition of organomodified clay to uncompatible polyethylene/ polyamide blends leads to acceleration of the thermomechanical degradation and thermooxidation during the melt processing of these blends $[29,30]$.

In this work, the photooxidation behaviour of lowdensity polyethylene (LDPE)/polyamide (PA) blends, containing polyamide 11 (PA11) (PAll is produced by the polymerization of 11-aminoundecanoic acid) or polyamide 6 (PA6) (PA6 is synthesized by ring-opening polymerization of caprolactam), has been investigated in the absence and presence of a small amount of commercial organomodified clay (OMMT). The complex multicomponent polymer systems have been prepared through an extrusion process to simulate industrial processing conditions. The formulated sheets have been subjected to UVB and the mechanical and structural changes of all investigated systems have been monitored as

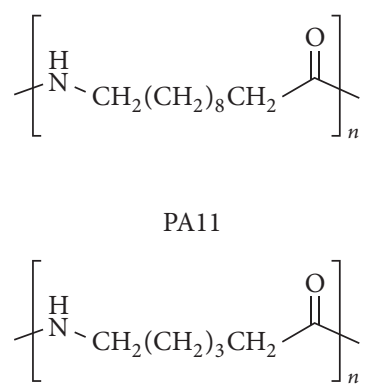

PA6

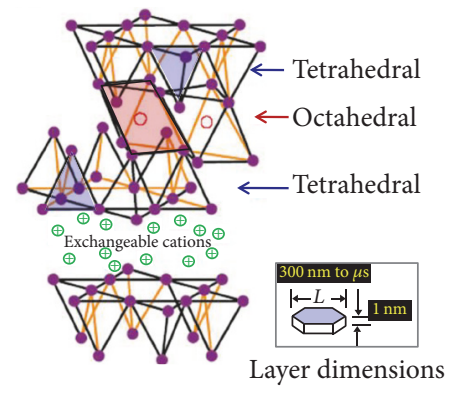

OMMT

$$
\begin{aligned}
& \text { - Al, Mg, Li, Fe } \\
& \text { - OH, O } \\
& \text { - Na, Li, Cs }
\end{aligned}
$$

Figure 1: Structural formulas of the used PA11, PA6, and OMMT. The structure of OMMT is taken from [23].

a function of the exposure time. Before the UVB exposure, accurate morphological and mechanical characterizations of the complex systems have been performed, in order to relate the rate of photodegradation to the morphological refinement of the blends upon OMMT.

\section{Experimental Part}

2.1. Materials and Blend Preparation. The used materials are as follows:

(i) Low-density polyethylene, LDPE, (Riblene ${ }^{\circledR}$ FC30, from Versalis S.p.A., Italy), with density $\rho=$ $0.922 \mathrm{~g} / \mathrm{cm}^{3}$ at $23^{\circ} \mathrm{C}$ and $\mathrm{MFI}_{190^{\circ}} \mathrm{C} / 2.16 \mathrm{~kg}$ of $0.27 \mathrm{~g} / 10^{\prime}$

(ii) Polyamide 6 (PA6) (Radilon ${ }^{\circledR}$ S, from Radici Group, Italy), which has density $\rho=1.13 \mathrm{~g} / \mathrm{cm}^{3}$ and intrinsic viscosity $[\eta]=1.5 \mathrm{dL} / \mathrm{g}$ measured at $30^{\circ} \mathrm{C}$ in 80 vol. $\%$ formic acid

(iii) Polyamide 11 (PA11) (Nylon 11 from Sigma-Aldrich), with glass transition temperature $T_{g}=46^{\circ} \mathrm{C}$, melting temperature $T_{m}=198^{\circ} \mathrm{C}$, and density $\rho=1.026 \mathrm{~g} / \mathrm{cm}^{3}$ at $25^{\circ} \mathrm{C}$

(iv) Organomodified montmorillonite (OMMT) (Cloisite $^{\circledR} 15 \mathrm{~A}$ from Southern Clay Products), modified by dimethyl-dihydrogenated tallow-quaternary ammonium cation, with concentration of the organomodifier of 125 meq. $/ 100 \mathrm{~g}$ clay and density $\rho=1.66 \mathrm{~g} / \mathrm{cm}^{3}$

The structural formulas of the used PA11, PA6, and OMMT are reported in Figure 1. The designations and compositions of the samples are summarized in Table 1.

The nanocomposite blends were prepared in two steps: first, the organoclay was compounded with the polymeric constituents of the blends using a corotating intermeshing twin-screw extruder (mod. OMC, Italy). The extrudate was cooled in water at the die exit, dried by air, and then granulated. The thermal profile was 140-200-240-240-240$240-220^{\circ} \mathrm{C}$ for blends containing PA6 and 120-160-210-210210-210-200 ${ }^{\circ} \mathrm{C}$ for blends containing PA1l; the screw speed was set to $\sim 100 \mathrm{rpm}$, corresponding to residence times of the 
TABLE 1: Blends' compositions.

\begin{tabular}{lcc}
\hline Sample & $\begin{array}{c}\text { Composition } \\
\text { [wt./wt. }+ \text { phr. }\end{array}$ & $\begin{array}{c}\text { Processing } \\
\text { temperature } \\
\left({ }^{\circ} \mathrm{C}\right)\end{array}$ \\
\hline LDPE/PA6 & $75 / 25$ & $240^{\circ} \mathrm{C}$ \\
LDPE/PA6/OMMT & $75 / 25+5$ phr. & $240^{\circ} \mathrm{C}$ \\
LDPE/PA11 & $75 / 25$ & $210^{\circ} \mathrm{C}$ \\
LDPE/PA11/OMMT & $75 / 25+5 \mathrm{phr}$. & $210^{\circ} \mathrm{C}$ \\
\hline
\end{tabular}

order of $\sim 150 \mathrm{~s}$. In order to produce sheets for the subsequent photooxidation analyses, the pellets were extruded again using a Brabender single screw extruder $(D=19 \mathrm{~mm}$, $L / D=25)$ attached to a Brabender Plasticorder PLE 651 and equipped with a ribbon head. The thermal profile of this second extrusion step was $240-240-240^{\circ} \mathrm{C}$ for blends containing PA6 and $210-210-210^{\circ} \mathrm{C}$ for blends containing PA11 and the screw speed was $50 \mathrm{rpm}$. The thickness of the samples was $\sim 85 \mu \mathrm{m}$. The unfilled PE/PA blends were processed in the same processing conditions, that is, the same processing temperatures and screw speeds.

2.2. Characterization. Wide-angle X-ray analyses (WAXD) were performed at room temperature in the reflection mode on a Siemens D-500 X-ray diffractometer with $\mathrm{Cu} \mathrm{K} \alpha$ radiation of wavelength of $0.1542 \mathrm{~nm}$. A scanning rate of $10^{\circ} \mathrm{C} \mathrm{min}^{-1}$ was used. The distance $d_{001}$ between the silicate layers of the organoclay in the nanocomposite blends was evaluated using Bragg's condition $d_{001}=n \lambda /(2 \sin \theta)$, where $\lambda$ is the wavelength, $\theta$ is the angle of incidence of the X-ray beam, and $n$ is an integer.

The microstructure of the blends was inspected using a scanning electron microscope (SEM), Leica 420. The observed cryofractured surfaces of the samples were previously coated with a thin layer of gold.

Mechanical tests were carried out according to ASTM test method D882 by using an Instron machine mod. 3365. The samples, stored for one week at room temperature and humidity, were tested at $1 \mathrm{~mm} / \mathrm{min}$ up to a strain of $10 \%$; then, the speed was increased up to $100 \mathrm{~mm} / \mathrm{min}$ until break. Young's modulus, tensile strength, and elongation at break were recorded, and the data reported represented the average values obtained by analyzing the results of eight tests per sample; the variability of mechanical tests was typically of the order of $\pm 5 \%$.

Fourier transform infrared (FTIR) spectra were evaluated using the Spectrum One Spectrometer by PerkinElmer and its Spectrum software. The spectra were obtained using 16 scans and a $4 \mathrm{~cm}^{-1}$ resolution. The variations of the carbonyl and hydroxyl band areas were determined from peak absorption area between 1850 and $1680 \mathrm{~cm}^{-1}$ and 3700 and $3300 \mathrm{~cm}^{-1}$, respectively. Moreover, the variation of peak area at $909 \mathrm{~cm}^{-1}$ was monitored (peak area between 980 and $950 \mathrm{~cm}^{-1}$ ). Measurements were obtained from the average of triplicate samples.

The artificial accelerated photooxidation tests were performed using a Q-UV chamber mounting eight UVB lamps.
TABLE 2: Interlayer distance for pristine OMMT and OMMTcontaining LDPE/PA blends.

\begin{tabular}{lc}
\hline Sample & $d_{001}(\mathrm{~nm})$ \\
\hline OMMT (pristine Cloisite 15A) & 3.14 \\
LDPE/PA11/OMMT & 3.43 \\
LDPE/PA6/OMMT & 3.58 \\
\hline
\end{tabular}

The weathering conditions, in the presence of oxygen, were 8 hours of light at $T=55^{\circ} \mathrm{C}$ and 4 hours of condensation at $\mathrm{T}=35^{\circ} \mathrm{C}$.

\section{Results and Discussion}

The distribution of the OMMT is a key factor for the morphology refinement and properties variations of polyolefin/polyamide blends. As widely documented [5, 21, 22], the OMMT particles are located preferentially inside the more hydrophilic polyamide phase and only a small amount, difficult to quantify, is located preferentially at the interface between the two polymeric phases.

To correlate the morphology changes of LDPE/PA11 and LDPE/PA6 blends, upon the OMMT addition, with the rate of photodegradation of these complex systems, accurate analysis of the structure of the blends has been performed through XRD and SEM observations. In Figure 2, the SEM micrographs of the investigated complex systems are shown. Both unfilled blends, that is, LDPE/PA11 and LDPE/PA6, show typical globular morphology of immiscible polymer blends (see Figures 2(a) and 2(c)). The minor polyamide phase is distributed as spherical droplets inside the polyolefin phase, although the dimension of the PA6 droplets is about $1-2 \mu \mathrm{m}$ and they are smaller than those of the PA1l droplets (dimension: 3-4 $\mu \mathrm{m}$ ). This can be due to the different viscosity ratios and interfacial tensions of the two blends [15]. Besides, the presence of microvoids, which surround the polyamide phase, indicates that interfacial adhesion is weak for both samples. It is very interesting to note that the presence of OMMT significantly modifies the morphology of both investigated blends; particularly, it is not possible to identify the polyamide droplets inside the polyolefin phase. The last can be understood considering that the OMMT nanoparticles are able to destroy the polyamide spheres because of their preferential localization in the more hydrophilic polyamide phase. In this way, the OMMT nanoparticles exert a compatibilizing effect and promote the morphology refinement, which is more evident for the LDPE/PA6 blend.

To deeply investigate the morphology modification of formulated blends upon OMMT addition, XRD analysis has been carried out (see Table 2). The calculated interlayer distance for OMMT in LDPE/PA6 is about $3.58 \mathrm{~nm}$, while in LDPE/PA11 it is about $3.43 \mathrm{~nm}$, highlighting enhanced intercalation between the silicate layers for the system containing PA6. Considering that the viscosity of PA6 at the processing conditions is about $10^{3} \mathrm{~Pa} \mathrm{~s}$ [31], which is higher than that of PA11 (about $3 \times 10^{2}$ Pa s [5]), higher shear stresses 


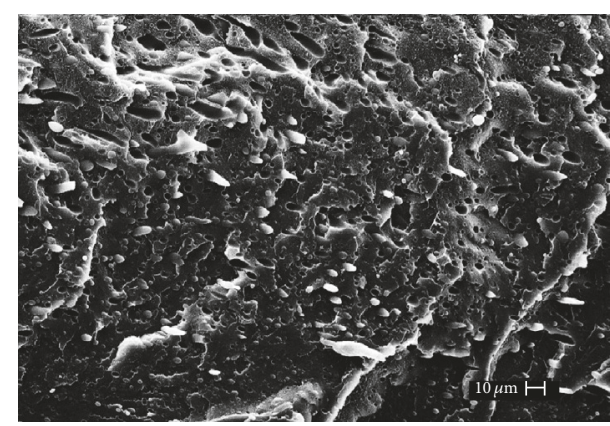

(a)

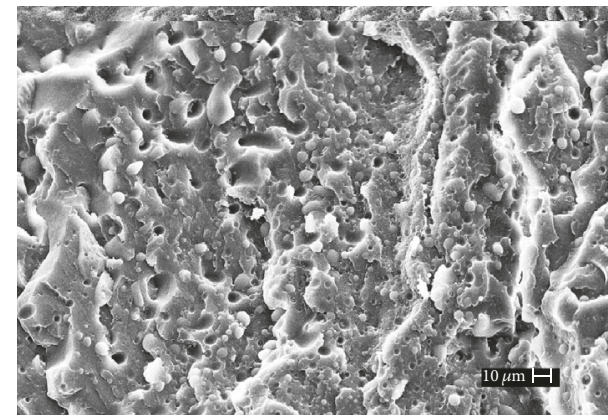

(c)

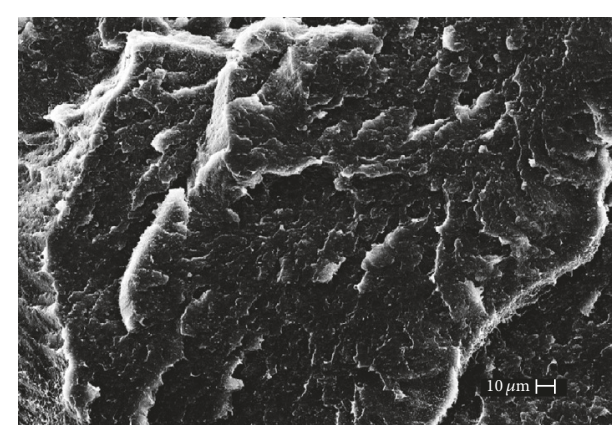

(b)

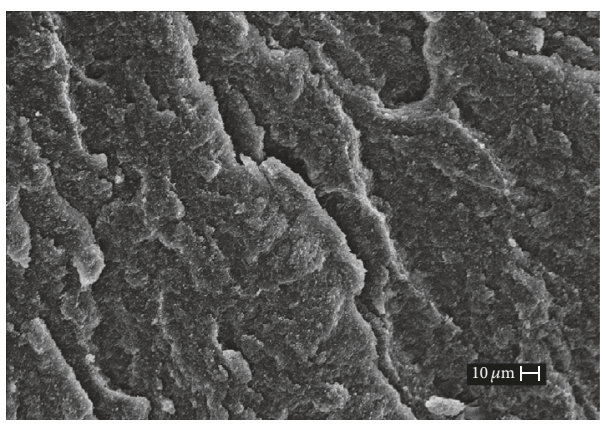

(d)

Figure 2: SEM micrographs of various hybrid blends: (a) LDPE/PA11, (b) LDPE/PA11/OMMT, (c) LDPE/PA6, and (d) LDPE/PA6/OMMT. The scale bars represent $10 \mu \mathrm{m}$. Micrographs (c) and (d) are taken from [21].

TABLE 3: Mechanical properties, that is, elastic modulus (E), tensile strength (TS), and elongation at break (EB), of the unfilled and OMMT-filled LDPE/PA blends.

\begin{tabular}{lccc}
\hline Sample & E (MPa) & TS $(\mathrm{MPa})$ & EB (\%) \\
\hline LDPE/PA11 & $195 \pm 9.5$ & $10.2 \pm 0.5$ & $52 \pm 2.5$ \\
LDPE/PA11/OMMT & $255 \pm 12.0$ & $11.1 \pm 0.6$ & $44 \pm 1.9$ \\
LDPE/PA6 & $231 \pm 11.3$ & $14.0 \pm 0.7$ & $92 \pm 3.5$ \\
LDPE/PA6/OMMT & $315 \pm 15.7$ & $15.0 \pm 0.7$ & $65 \pm 3.0$ \\
\hline
\end{tabular}

are experienced by the clay during melt mixing of the PA6based blend, thus explaining the difference in the interlayer distances.

The mechanical properties of all the investigated complex systems have been evaluated and the values of the elastic modulus, E, tensile strength, TS, and elongation at break, EB, are reported in Table 3. It can be observed that the increase of the elastic modulus due to the presence of OMMT is about $30 \%$ and 36\% for PA11- and PA6-containing systems, respectively, while the values of tensile strength remain almost unchanged. Differently, a slight decrease of the values of the elongation at break can be observed for both PA11- and PA6containing systems. The improvement of the blend rigidity can be related to the morphology refinement of both blends upon OMMT addition. Indeed, the refinement of blends morphology induced by the OMMT and the enhancement of the interfacial adhesion in the LDPE/PA systems, improving the state of the interface, allow obtaining high-performance complex systems.

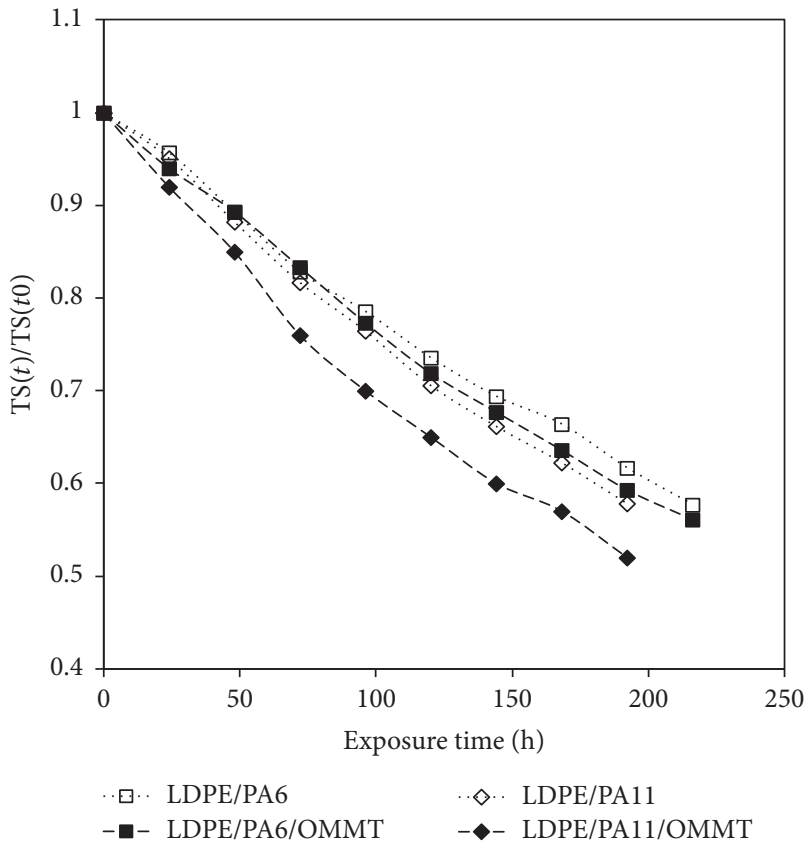

Figure 3: Dimensionless tensile strength as a function of the exposure time of the unfilled and OMMT-filled LDPE/PA blends.

The photooxidation behaviour of the formulated blends and nanocomposites has been investigated through mechanical and FTIR analyses. In Figures 3 and 4, the trends of the dimensionless tensile strength, TS, and elongation at break, 


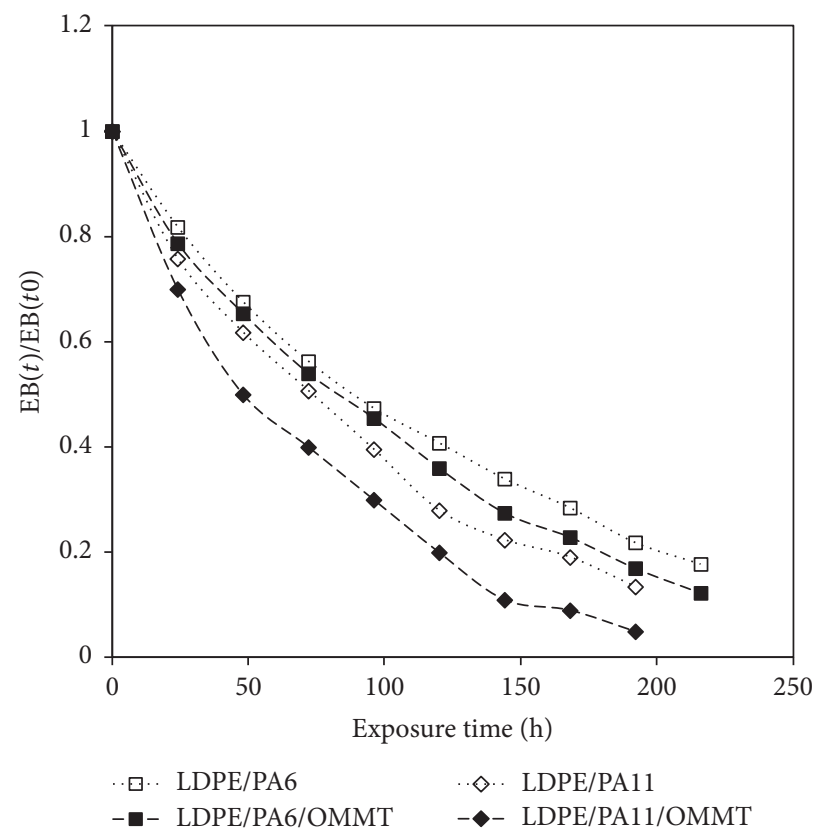

FIGURE 4: Dimensionless elongation at break as a function of the exposure time of the unfilled and OMMT-filled LDPE/PA blends.
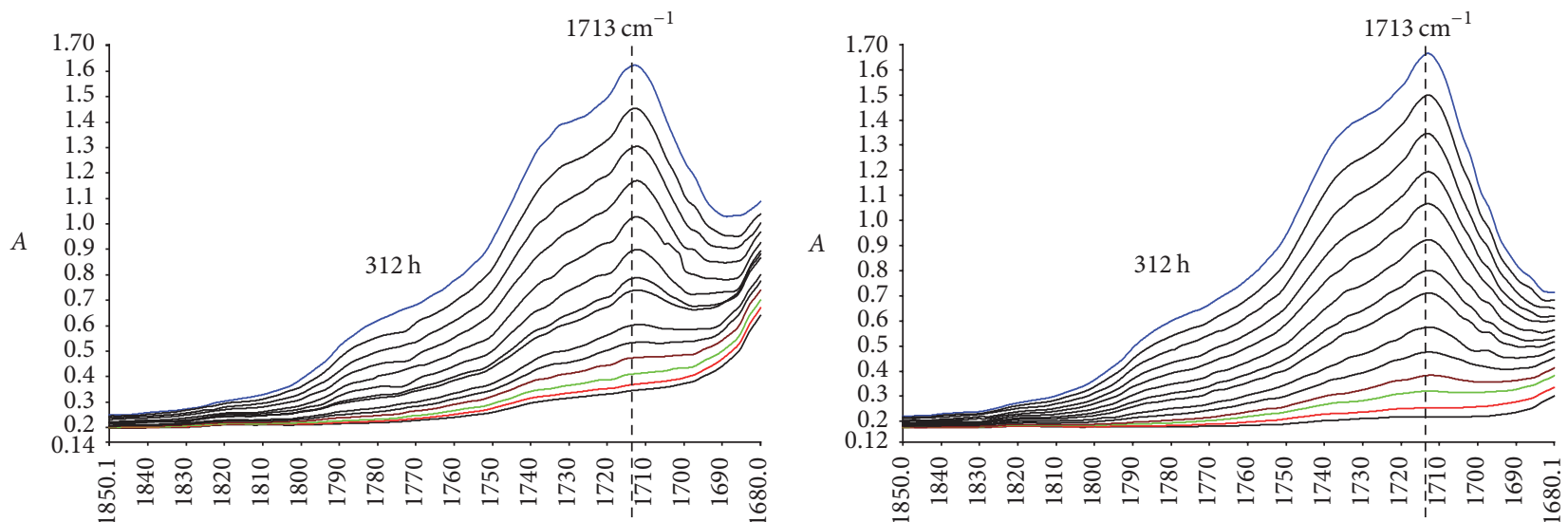

\section{$\left(\mathrm{cm}^{-1}\right)$}

(a)

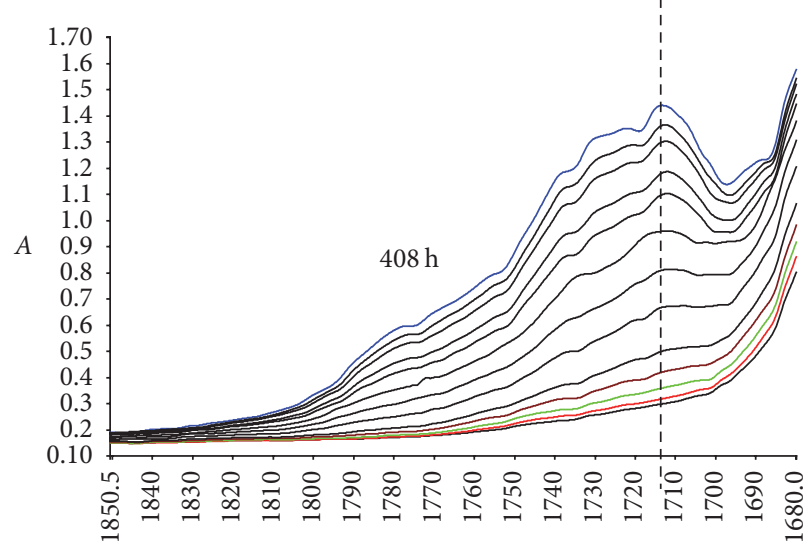

$\left(\mathrm{cm}^{-1}\right)$

(c)
0
$\circ 0$
$\circ$

$\left(\mathrm{cm}^{-1}\right)$

(b)

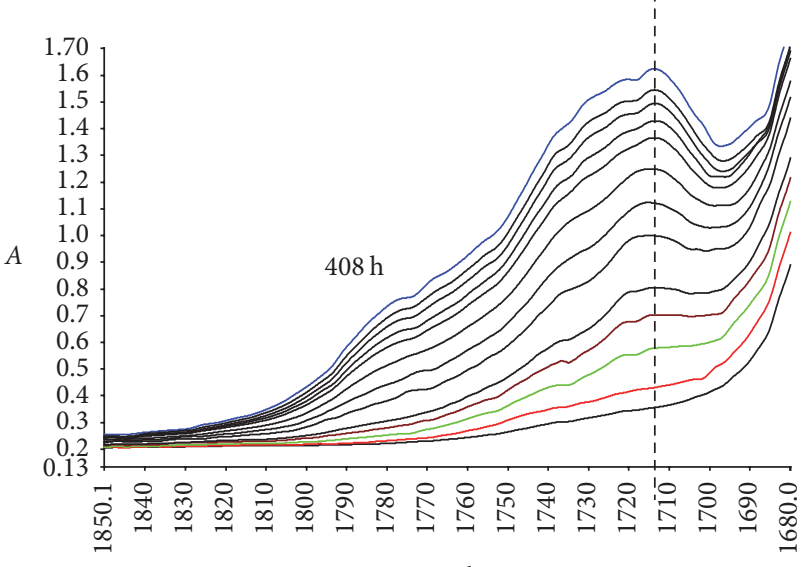

$\left(\mathrm{cm}^{-1}\right)$

(d)

FIGURE 5: FTIR spectra (range: $1850-1680 \mathrm{~cm}^{-1}$ ) as a function of the exposure time of various hybrid blends: (a) LDPE/PA11, (b) LDPE/PA11/OMMT, (c) LDPE/PA6, and (d) LDPE/PA6/OMMT (the last spectra of each sample corresponding to the spectra at maximum indicated exposure time). 


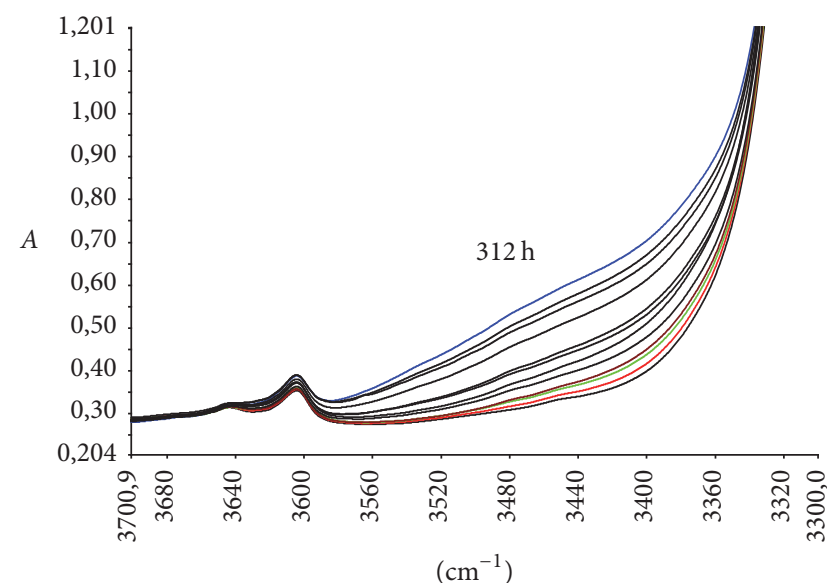

(a)

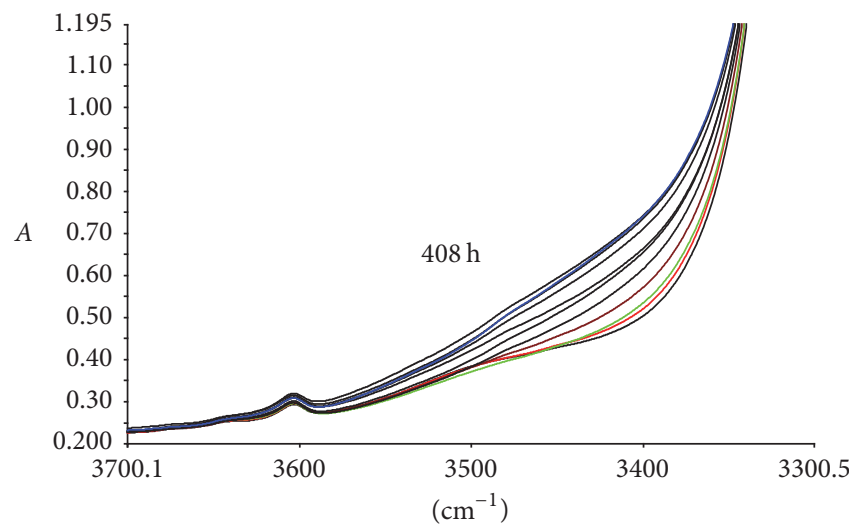

(c)

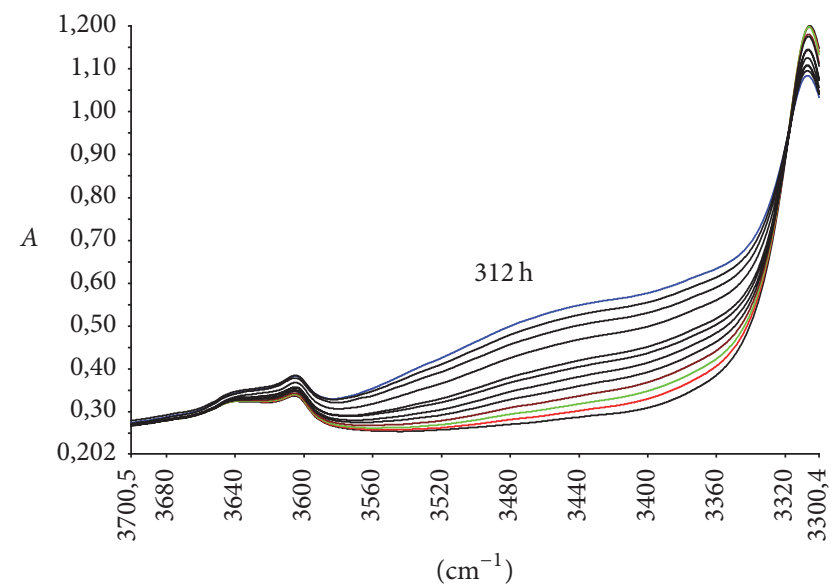

(b)

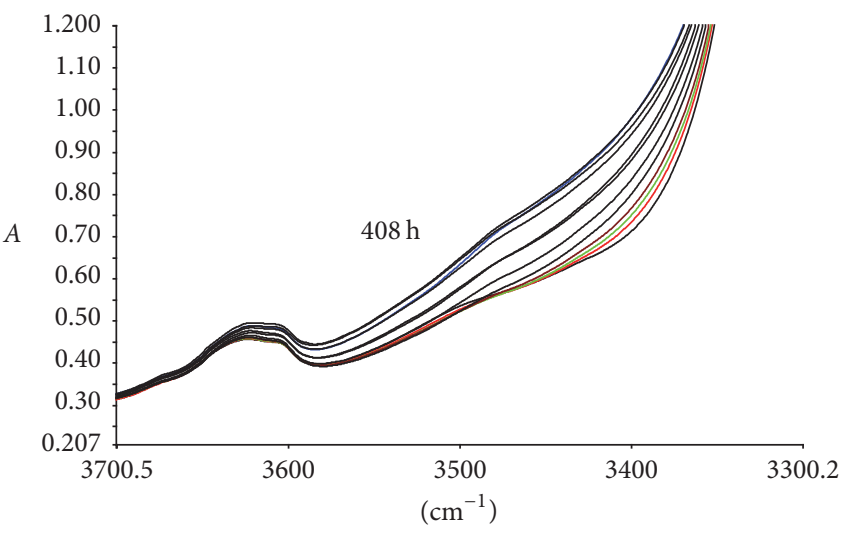

(d)

FIGURE 6: FTIR spectra (range: $3700-3300 \mathrm{~cm}^{-1}$ ) as a function of the exposure time of various hybrid blends: (a) LDPE/PA11, (b) LDPE/PA11/OMMT, (c) LDPE/PA6, and (d) LDPE/PA6/OMMT (the last spectra of each sample corresponding to the spectra at maximum indicated exposure time).

$\mathrm{EB}$, as a function of the exposure time, are reported. The dimensionless values of the properties at break have been calculated as a ratio between the values of TS and EB at different exposure times and the values of the unexposed samples. As a function of the photooxidation time, decay of TS and EB for all investigated samples can be noticed, as a result of the materials' structural modifications occurring upon UVB exposure. Both LDPE-based blends display similar decay of the mechanical properties and show comparable values of half-time of the elongation at break, that is, the time at which $\mathrm{EB}$ is one half of its initial value. The addition of OMMT leads to acceleration of the blend degradation phenomena and the decay of the mechanical properties is more rapid than that of the respective unfilled blends. The detrimental effect of OMMT on the photooxidative resistance is more pronounced for the PA11-containing blend with respect to the PA6-containing one. The last can be explained considering that the addition of OMMT in the LDPE/PA6 blend induces more pronounced morphology refinement than that induced in the LDPE/PA11 one.

Furthermore, the photooxidation behaviour of all the investigated blends has been followed by FTIR analysis and in Figures 5-7 the spectra in the carbonyl $\left(1850-1680 \mathrm{~cm}^{-1}\right)$, hydroxyl $\left(3700-3300 \mathrm{~cm}^{-1}\right)$, and vinyl unsaturated bonds (980-950 $\left.\mathrm{cm}^{-1}\right)$ range, at different exposure times, are reported. As well known, the progress of the photodegradation of LDPE proceeds through the formation of oxygencontaining groups, such as carbonyl groups (namely, carboxylic acid and ketones at $1713 \mathrm{~cm}^{-1}$, esters at $1730 \mathrm{~cm}^{-1}$, and lactones at $1780 \mathrm{~cm}^{-1}$ ) and hydroxyl groups (free or linked $\mathrm{OH}$ groups) and the formation of vinyl unsaturation (vinyl groups at $909 \mathrm{~cm}^{-1}$ ) $[23,26]$; differently, the progress of the photodegradation of PA, in the presence of humidity, proceeds through random chain scission reactions and the formation of carbonyl and/or carboxyl groups (shoulder at $1711 \mathrm{~cm}^{-1}$ ) [21]. In this study, the samples for FTIR analysis have been subjected to UVB exposure for longer times than those for the mechanical tests because in the latter case the blends become brittle at short exposure times. To follow the photooxidation progress of the unfilled and OMMT-filled blends, the areas of the peaks at different ranges, carbonyl, hydroxyl, and vinyl unsaturation, have been calculated and reported as a function of the exposure time in Figures 8-10. 


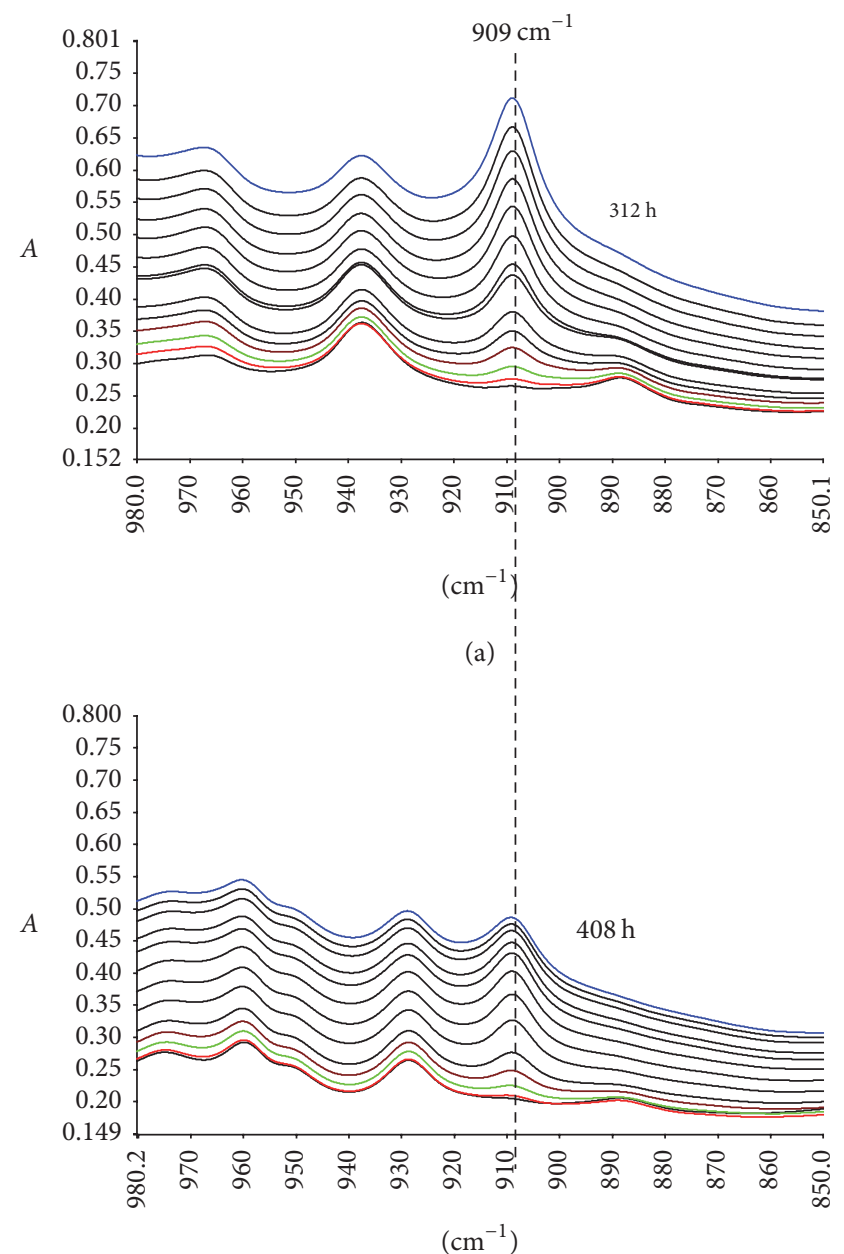

(c)

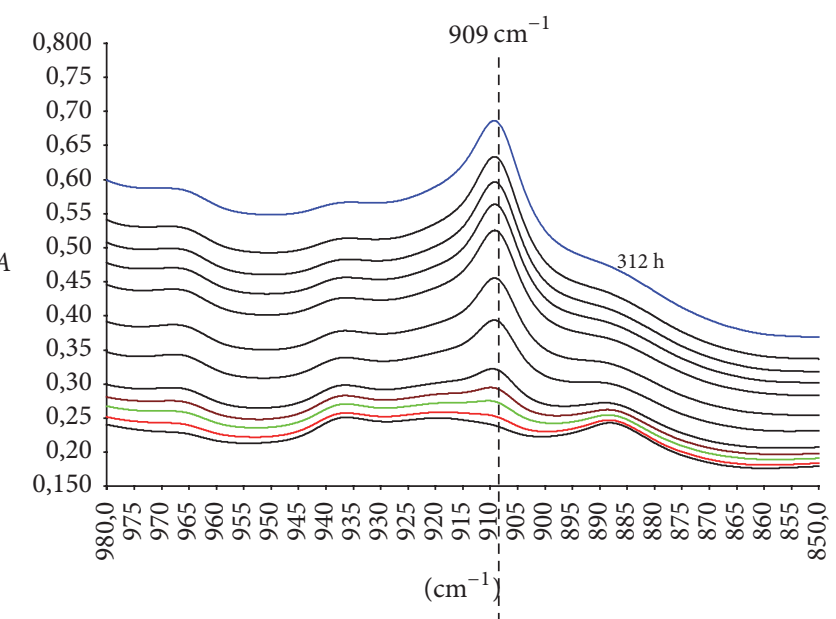

(b)

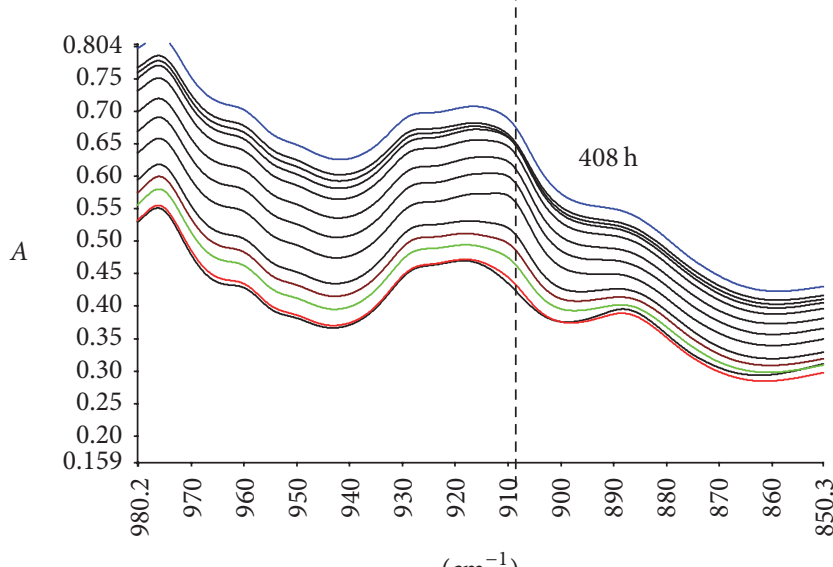

(d)

FIGURE 7: FTIR spectra (range: $980-950 \mathrm{~cm}^{-1}$ ) as a function of the exposure time of various hybrid blends: (a) LDPE/PA11, (b) LDPE/PA11/OMMT, (c) LDPE/PA6, and (d) LDPE/PA6/OMMT (the last spectra of each sample corresponding to the spectra at maximum indicated exposure time).

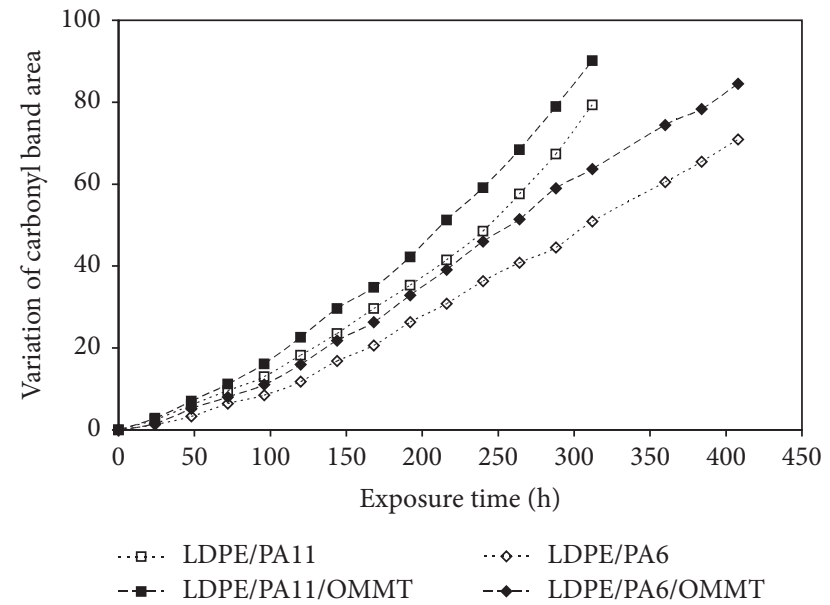

FIGURE 8: Variation of the carbonyl band area as a function of the exposure time of the unfilled and OMMT-filled blends.

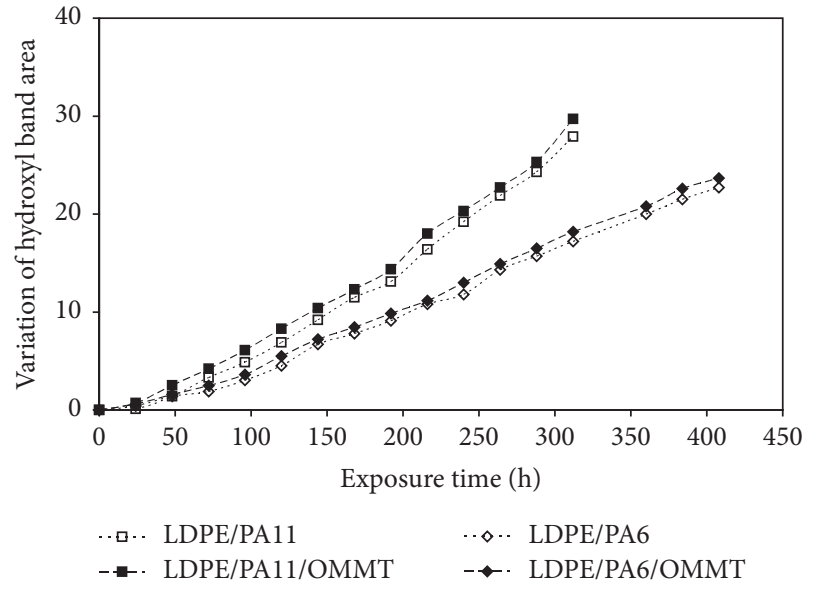

FIgURE 9: Variation of the hydroxyl band area as a function of the exposure time of the unfilled and OMMT-filled blends. 


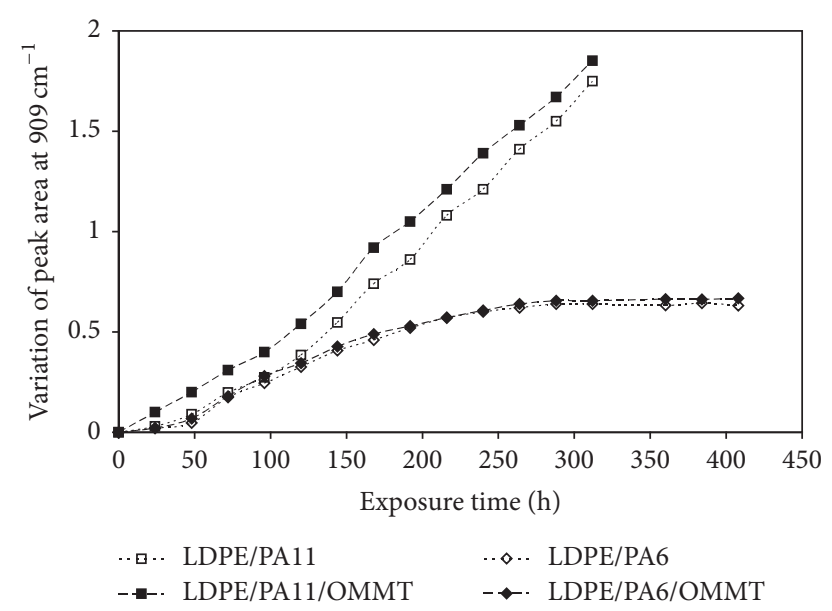

FIgURE 10: Variation of peak area at $909 \mathrm{~cm}^{-1}$ as a function of the exposure time of the unfilled and OMMT-filled blends.

It can be noted that the trends of carbonyl, hydroxyl, and vinyl formations follow the same trends as the properties at break and the differences between the unfilled and OMMTfilled systems become more pronounced with increasing the exposure time. The presence of OMMT accelerates the formation of oxygen-containing groups, whose accumulation is associated with the progress of the photooxidation. Indeed, as expected, the accumulation of the carbonyl and hydroxyl groups is more pronounced for the OMMT-filled blends.

Concerning the photooxidative behaviour of the LDPE/PA6-based samples, it is worth noting that the growth of the vinyl unsaturation amount reaches a plateau after about $250 \mathrm{~h}$ of exposure and the addition of OMMT does not affect the trends of the vinyl formations. Furthermore, the values of areas of carbonyl, hydroxyl, and vinyl peaks for LDPE/PA6-based systems are lower than those of the LDPE/PA11-based systems, indicating that a more refined morphology is beneficial in mitigating the detrimental effects of the filler in terms of photooxidative resistance.

\section{Conclusions}

Unfilled and OMMT-filled LDPE/PA blends have been formulated through a two-step procedure, extrusion and sheet formulation, and their photooxidative behaviour has been evaluated through mechanical and spectroscopic analysis. Preliminary tests performed on unexposed samples showed that OMMT addition leads to refinement of the blends' morphology with consequent improvement of the mechanical properties. Concerning the photooxidative resistance of the formulated samples, the addition of OMMT slightly accelerates the photodegradation phenomena of unfilled blends but this detrimental effect is mitigated by the morphology refinement induced by the nanoclay.

\section{Conflicts of Interest}

The authors declare that there are no conflicts of interest regarding the publication of this paper.

\section{References}

[1] M. M. Rueda, M. Auscher, R. Fulchiron et al., "Rheology and applications of highly filled polymers: a review of current understanding," Progress in Polymer Science, vol. 66, pp. 22-53, 2017.

[2] A. Sionkowska, "Current research on the blends of natural and synthetic polymers as new biomaterials: review," Progress in Polymer Science, vol. 36, no. 9, pp. 1254-1276, 2011.

[3] B. Li, N. Emami, G. Gong, and W. Song, "Applications of nanomaterials in multifunctional polymer nanocomposites," Journal of Nanomaterials, vol. 2016, Article ID 5790194, 1 page, 2016.

[4] S. Al-Malaika and N. Suharty, "Reactive processing of polymers: mechanisms of grafting reactions of functional antioxidants on polyolefins in the presence of a coagent," Polymer Degradation and Stability, vol. 49, no. 1, pp. 77-89, 1995.

[5] G. Filippone, N. T. Dintcheva, F. P. La Mantia, and D. Acierno, "Selective localization of organoclay and effects on the morphology and mechanical properties of LDPE/PA11 blends with distributed and co-continuous morphology," Journal of Polymer Science, Part B: Polymer Physics, vol. 48, no. 5, pp. 600-609, 2010.

[6] M. Nofar, M.-C. Heuzey, P. J. Carreau, and M. R. Kamal, "Effects of nanoclay and its localization on the morphology stabilization of PLA/PBAT blends under shear flow," Polymer (United Kingdom), vol. 98, pp. 353-364, 2016.

[7] J. Huang, C. Mao, Y. Zhu, W. Jiang, and X. Yang, "Control of carbon nanotubes at the interface of a co-continuous immiscible polymer blend to fabricate conductive composites with ultralow percolation thresholds," Carbon, vol. 73, pp. 267-274, 2014.

[8] Y. Pan, X. Liu, X. Hao, Z. Starý, and D. W. Schubert, "Enhancing the electrical conductivity of carbon black-filled immiscible polymer blends by tuning the morphology," European Polymer Journal, vol. 78, pp. 106-115, 2016.

[9] P. J. Brigandi, J. M. Cogen, and R. A. Pearson, "Electrically conductive multiphase polymer blend carbon-based composites," Polymer Engineering and Science, vol. 54, no. 1, pp. 1-16, 2014.

[10] R. J. Sengwa and S. Choudhary, "Structural characterization of hydrophilic polymer blends/montmorillonite clay nanocomposites," Journal of Applied Polymer Science, vol. 131, no. 16, Article ID 40617, 2014.

[11] J. P. Mofokeng and A. S. Luyt, "Morphology and thermal degradation studies of melt-mixed poly(lactic acid) (PLA)/poly $(\varepsilon-$ caprolactone) (PCL) biodegradable polymer blend nanocomposites with $\mathrm{TiO}_{2}$ as filler," Polymer Testing, vol. 45, article 4440, pp. 93-100, 2015.

[12] Y. S. Lipatov, "Polymer blends and interpenetrating polymer networks at the interface with solids," Progress in Polymer Science (Oxford), vol. 27, no. 9, pp. 1721-1801, 2002.

[13] R. Bahrami, T. I. Löbling, H. Schmalz, A. H. Müller, and V. Altstädt, "Synergistic effects of Janus particles and triblock terpolymers on toughness of immiscible polymer blends," Polymer, vol. 109, pp. 229-237, 2017.

[14] A. Taguet, P. Cassagnau, and J.-M. Lopez-Cuesta, "Structuration, selective dispersion and compatibilizing effect of (nano)fillers in polymer blends," Progress in Polymer Science, vol. 39, no. 8, pp. 1526-1563, 2014.

[15] M. S. De Luna and G. Filippone, "Effects of nanoparticles on the morphology of immiscible polymer blends - challenges and opportunities," European Polymer Journal, vol. 79, pp. 198-218, 2016. 
[16] M. Psarski, M. Pracella, and A. Galeski, "Crystal phase and crystallinity of polyamide 6/functionalized polyolefin blends," Polymer, vol. 41, no. 13, pp. 4923-4932, 2000.

[17] D. Sémeril, E. Passaglia, C. Bianchini, M. Davies, H. Miller, and F. Ciardelli, "Reactive blending of polyamides with different carbonyl containing olefin polymers," Macromolecular Materials and Engineering, vol. 288, no. 6, pp. 475-483, 2003.

[18] S. Therias, N. T. Dintcheva, J.-L. Gardette, and F. P. La Mantia, "Photooxidative behaviour of polyethylene/polyamide- 6 blends," Polymer Degradation and Stability, vol. 95, no. 4, pp. 522-526, 2010.

[19] P. A. Christensen, T. A. Egerton, S. M. Martins-Franchetti, C. Jin, and J. R. White, "Photodegradation of polycaprolactone/ poly(vinyl chloride) blend," Polymer Degradation and Stability, vol. 93, no. 1, pp. 305-309, 2008.

[20] F. P. La Mantia and N. T. Dintcheva, "Photooxidation and stabilization of photooxidized polyethylene and of its monopolymer blends," Journal of Applied Polymer Science, vol. 91, no. 4, pp. 2244-2255, 2004.

[21] N. T. Dintcheva, G. Filippone, F. P. La Mantia, and D. Acierno, "Photo-oxidation behaviour of polyethylene/polyamide 6 blends filled with organomodified clay: improvement of the photo-resistance through morphology modification," Polymer Degradation and Stability, vol. 95, no. 4, pp. 527-535, 2010.

[22] M. C. Mistretta, P. Fontana, M. Ceraulo, M. Morreale, and F. P. La Mantia, "Effect of compatibilization on the photooxidation behaviour of polyethylene/polyamide 6 blends and their nanocomposites," Polymer Degradation and Stability, vol. 112, pp. 192-197, 2015.

[23] N. T. Dintcheva, S. Al-Malaika, and F. P. La Mantia, "Effect of extrusion and photo-oxidation on polyethylene/clay nanocomposites," Polymer Degradation and Stability, vol. 94, no. 9, pp. 1571-1588, 2009.

[24] H. Qin, S. Zhang, H. Liu, S. Xie, M. Yang, and D. Shen, "Photooxidative degradation of polypropylene/montmorillonite nanocomposites," Polymer, vol. 46, no. 9, pp. 3149-3156, 2005.

[25] W. Xie, Z. Gao, W.-P. Pan, D. Hunter, A. Singh, and R. Vaia, "Thermal degradation chemistry of alkyl quaternary ammonium Montmorillonite," Chemistry of Materials, vol. 13, no. 9, pp. 2979-2990, 2001.

[26] F. P. la Mantia, N. T. Dintcheva, V. Malatesta, and F. Pagani, "Improvement of photo-stability of LLDPE-based nanocomposites," Polymer Degradation and Stability, vol. 91, no. 12, pp. 3208-3213, 2006

[27] S. Morlat-Therias, B. Mailhot, J.-L. Gardette, C. Da Silva, B. Haidar, and A. Vidal, "Photooxidation of ethylene-propylenediene/montmorillonite nanocomposites," Polymer Degradation and Stability, vol. 90, no. 1, pp. 78-85, 2005.

[28] A. Nuzzo, S. Coiai, S. C. Carroccio, N. T. Dintcheva, C. Gambarotti, and G. Filippone, "Heat-resistant fully bio-based nanocomposite blends based on poly(lactic acid)," Macromolecular Materials and Engineering, vol. 299, no. 1, pp. 31-40, 2014.

[29] M. C. Mistretta, M. Morreale, and F. P. La Mantia, "Thermomechanical degradation of polyethylene/polyamide 6 blend-clay nanocomposites," Polymer Degradation and Stability, vol. 99, no. 1, pp. 61-67, 2014.

[30] G. Filippone, S. C. Carroccio, G. Curcuruto, E. Passaglia, C. Gambarotti, and N. T. Dintcheva, "Time-resolved rheology as a tool to monitor the progress of polymer degradation in the melt state - Part II: Thermal and thermo-oxidative degradation of polyamide 11/organo-clay nanocomposites," Polymer (United Kingdom), vol. 73, Article ID 18002, pp. 102-110, 2015.
[31] G. Filippone, N. T. Dintcheva, F. P. La Mantia, and D. Acierno, "Using organoclay to promote morphology refinement and cocontinuity in high-density polyethylene/polyamide 6 blends Effect of filler content and polymer matrix composition," Polymer, vol. 51, no. 17, pp. 3956-3965, 2010. 

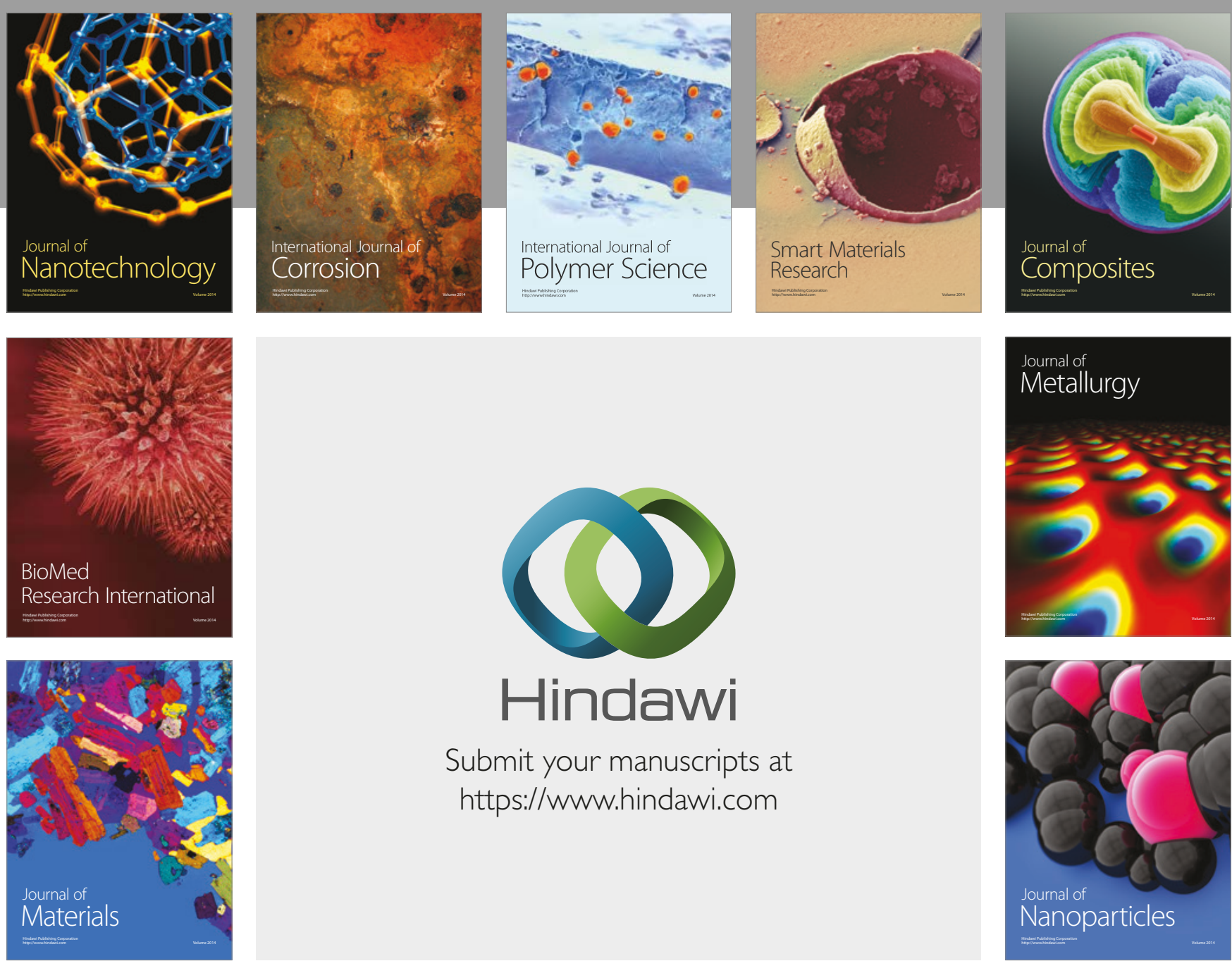

\section{Hindawi}

Submit your manuscripts at

https://www.hindawi.com
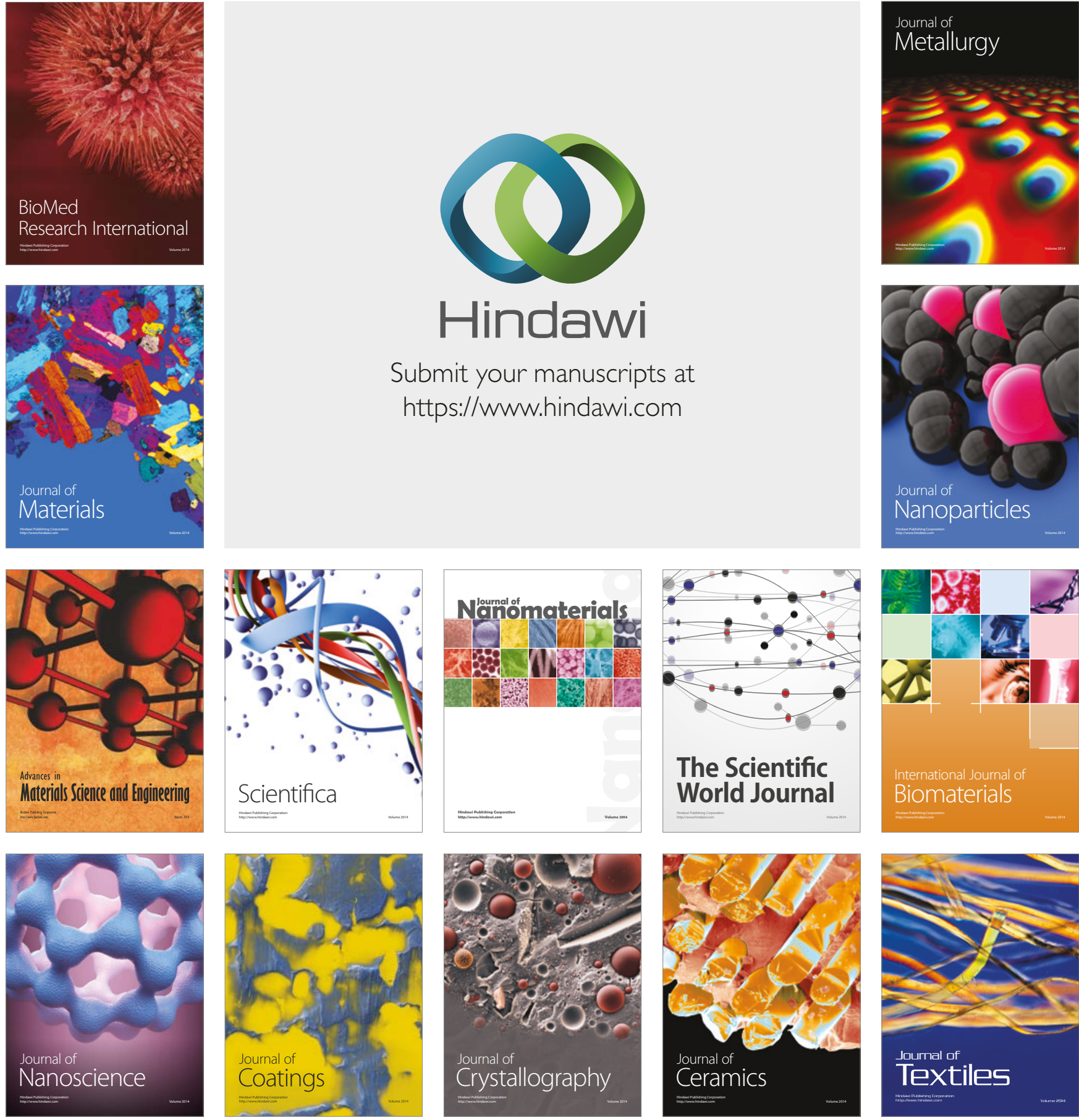

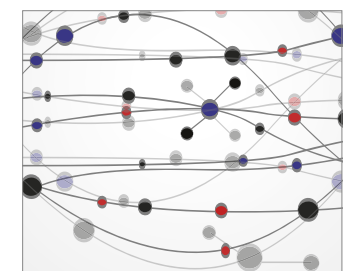

The Scientific World Journal
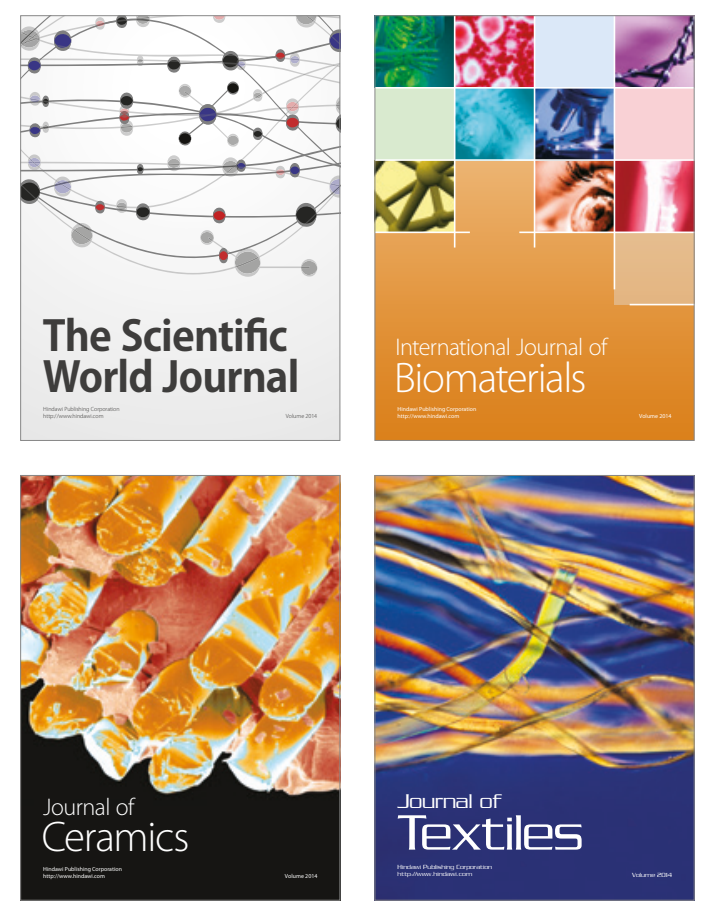